\title{
A Brief Report of Caregiver Needs and Resource Utilization During Pediatric Hematopoietic Stem Cell Transplantation
}

\author{
Deborah K. Mayer, PhD, RN, AOCN, FAAN, Hocine Tighiouart, MS, Norma Terrin, PhD, \\ Susan Stewart, BA, Emily Peterson, BA, Stefanie Jeruss, MS, and Susan K. Parsons, MD, \\ MRP
}

Deborah K. Mayer PhD, RN, AOCN, FAAN, is an associate professor at the School of Nursing, University of North Carolina at Chapel Hill, and member of the UNC Lineberger Comprehensive Cancer Center. Hocine Tighiouart MS, is a statistician with the Institute for Clinical Research and Health Policy Studies at the Tufts Medical Center. Norma Terrin PhD, is an associate professor at Tufts University School of Medicine and the Sackler School of Graduate Biomedical Sciences, and senior statistician in the Institute for Clinical Research and Health Policy Studies at Tufts Medical Center. Susan Stewart is the director, Blood \& Marrow Transplant Information Network, and editor of the BMT Newsletter. Emily Peterson is a resource development specialist in the Office of Patient Advocacy of the National Marrow Donor Program. Stefanie Jeruss MS, was a research coordinator at the Institute for Clinical Research and Health Policy Studies at Tufts Medical Center during this study. Susan K. Parsons MD, MRP, is the director of the Health Institute and the Center on Child and Family Outcomes at the Institute for Clinical Research and Health Policy Studies at Tufts Medical Center. She is an associate professor of medicine and pediatrics at the Tufts University School of Medicine.

\begin{abstract}
Hematopoietic stem cell transplantation (HSCT) is used to eradicate disease and restore normal hematopoietic, immunologic, and/or metabolic functioning. HSCT is a complex treatment that is physiologically and psychologically demanding on the recipient, caregiver, and family. The purpose of this study was to identify needs and resources of family caregivers of pediatric HSCT recipients during the first year after transplant. Parental caregivers $(n=161)$ completed an online survey. The most cited sources of information were the HSCT team (87.7\%), books and other print materials $(83.1 \%)$, and the Internet $(81.5 \%)$. However, more than half of the respondents reported that finding resources and services was a problem. More than half identified managing the emotional and social impact of the transplant on their child, posttransplant and follow-up care, practical strategies for caregiving, maintaining the family, and taking care of themselves during this first year as important topics to address. Adequately and regularly assessing caregiver and family needs and providing resources to meet those needs, especially during transitions in care, are important components of transplant care.
\end{abstract}

\section{Keywords}

needs assessment; caregiving; bone marrow transplantation; adaptation; Internet; online survey

Hematopoietic stem cell transplantation (HSCT) is a treatment to eradicate disease and restore normal hematopoietic, immunologic, and/or metabolic functioning. Since its

(C) 2009 by Association of Pediatric Hematology/Oncology Nurses

Address for correspondence: Deborah K. Mayer, PhD, RN, AOCN, FAAN, University of North Carolina-Chapel Hill, School of Nursing, Carrington Hall \#7460, Chapel Hill, NC 27599-7460; dmayer@unc.edu. 
inception more than 30 years ago, improvements in stem cell sources, donor types, tissue matching, and supportive care have contributed to both the number who receive this treatment and those who survive it. In North America, almost 19000 HSCTs were performed in 2005 , of which approximately $14 \%(\mathrm{n}=2620)$ were in children. ${ }^{1}$ HSCT is currently being performed in more than 100 specialized pediatric centers throughout the United States. Many of these children, like other HSCT recipients, are away from home for varying lengths of time because of the intensive nature of the procedure and the long recovery periods.

HSCT is a complex treatment that is both physiologically and psychologically demanding on the recipient, caregiver, and family (Eldredge et al., 2006; Foxall \& Gaston-Johansson, 1996; Grimm, Zawacki, Mock, Krumm, \& Frink, 2000; Parsons et al., 2006; Wochna, 1997). The HSCT process begins with a prolonged and intensive hospitalization for the preparative or conditioning regimen, for transplant, and for some time posttransplant. Following the HSCT procedure, there is physical and social isolation and intensive outpatient management at the transplant center for varying lengths of time. The caregiver, usually a parent in the case of a child and the spouse in the case of an adult, is required to actively participate in care both during the initial transplantation period and for months or years afterward. Although health providers' understanding is growing about the healthrelated quality of life of HSCT survivors and selected problems faced by their caregivers, less is known about HSCT-related needs of families or potential remediation to enhance outcomes.

Stetz, McDonald, and Compton (1996) conducted 4 focus groups of 19 family members within 3 months of HSCT in adult recipients. They identified concerns related to preparing for caregiving, managing care, facing the challenges, developing supportive strategies, and discovering unanticipated rewards and benefits of transplant. In a qualitative study of 7 parents of children receiving HSCT, White (1994) identified 6 themes in the posttransplant transition period: the return home, changing relationships, working with this (the process of dealing with the transplant emotionally and financially), learning the rules, the new norm, and the uncertain future. Although much has changed in the HSCT process, little work has been done since the 1990s with regard to evaluating HSCT caregiver needs.

\section{Conceptual Framework}

Sullivan-Bolyai and colleagues identified 4 major caregiving responsibilities for the direct and indirect care of children with chronic conditions (Sullivan-Bolyai, Knafl, Sadler, \& Gilliss, 2004; Sullivan-Bolyai, Sadler, Knafl, \& Gilliss, 2003). The caregiving responsibilities include (a) managing the illness, which includes hands-on care, monitoring and interpreting signs and symptoms, problem solving, and decision making; (b) maintaining the family unit, including balancing illness and family demands while at the same time attempting to meet the health and developmental needs of each family member; (c) maintaining self, including physical, emotional, and spiritual health of the caregiver; and (d) identifying, accessing, and coordinating resources, which involves assessing and negotiating community resources including health care providers. These responsibilities provide the organizing framework for analyzing and presenting these results. Although the purpose of this study was to identify needs and resources during the first year after transplant of family caregivers of pediatric HSCT recipients, the focus of this brief report will be on identifying, accessing, and coordinating resources (personal, informational, or

\footnotetext{
${ }^{1}$ Note

Center for International Blood and Marrow Transplant Research, unpublished data, 2009.
} 
instrumental such as helping with routine household activities [shopping, cooking, housekeeping]) by families during this time.

\section{Method}

The Tufts' investigators partnered with Blood \& Marrow Transplant Information Network (BMT InfoNet), a national nonprofit HSCT advocacy group, to conduct an online survey to access parents through its organization. This allowed for greater diversity and sample size than going through any one institution because the number of pediatric transplants performed annually through any one center is relatively small.

\section{Online Survey Development}

Five online focus groups were conducted with parental caregivers and health care providers of pediatric HSCT recipients to identify issues that affect the family during this process (Mayer, Jeruss, \& Parsons, 2006). The HSCT Needs Assessment Survey items were created from themes identified from these focus groups. They included learning more about the HSCT and the care of their child, family and sibling needs, housing and transportation assistance, financial impact, household and work adjustments, insurance problems, communication with the health care team, accessing resources such as finding support groups or financial aid, and caregiving roles and responsibilities. Most response choices were nominal (yes/no, helpful/not helpful). Once the item content was finalized, an online survey software company, Zoomerang, was used to implement the survey. A beta version of the survey was launched and reviewed by clinical and survey experts and pilot tested by a convenience sample of 27 parental caregivers. Based on their feedback, minor modifications were made before launching the survey (eg, adding additional responses to questions about work and including stepsiblings and half siblings to the definition of siblings). The final survey consisted of 48 questions ( 5 questions had skip patterns) over 22 screen pages and included questions concerning patient and caregiver demographics, caregiver experiences and needs during the transplant process (defined as any time during the first year of the transplant), and needs regarding managing the illness, maintaining the family unit and self, and identifying, accessing, and coordinating resources. The online survey took approximately 15 minutes to complete.

\section{Human Subjects' Protection}

The investigators obtained approval from the Tufts Medical Center Institutional Review Board to conduct this online survey. Having obtained a waiver of documentation, the elements of informed consent were provided in the e-mail invitation to participate and on the first screen page of the survey. A statement "clicking below indicates that I agree to participate" that would only allow the participant to proceed if they selected "yes" was included. Other than an e-mail address, personally identifying information was not collected.

\section{Participant Identification and Eligibility (Eysenbach, 2004)}

BMT InfoNet advertised and provided access to the open survey in its electronic and paper newsletter and through its e-mail distribution list. Eligibility included being a parental caregiver, at least 18 years of age, of a pediatric HSCT recipient and being able to access the survey online. No incentives were offered for participation.

The survey was launched on January 23, 2006, and closed on February 23, 2006. The pilot survey included data from 27 parental caregivers (of the 34 invited to participate from this study's parents' user group). There were 154 responders to the national survey among 231 site visits; the participation rate was $66.6 \%$ (154/231). Of the 154, 18 participants were excluded who responded to 3 or fewer questions. The completion rate was $88.3 \%(136 / 154)$. 
Two additional respondents were excluded because the child's transplant had occurred more than 20 years earlier. The final evaluable sample was 134 . The total sample included in this report is 161 ( 27 pilot +134 evaluable survey responders). No formal system was used to prevent multiple entries from the same individual. Descriptive statistics were calculated for all survey responses. Sixty-two parental caregivers also chose to add comments at the end of the survey; these comments are integrated throughout the results section.

\section{Sample}

Of the 161 parental caregivers, most were mothers $(86.7 \%)$ between 30 and 49 years of age $(80 \%)$. They were predominantly white $(96.2 \%)$ with at least some college education (61.8\%). Their child had received an HSCT a median of 4 years (range, 1-20 years) prior to survey completion (Table 1). Parents reported that their child had the HSCT because the child had cancer (80.8\%) and was doing well since the transplant (61.2\%), $23.1 \%$ were dealing with transplant issues, $1.5 \%$ had disease recurrence, and in $14.2 \%$ of the cases the child had died.

\section{Results}

\section{Identifying, Accessing, and Coordinating Resources}

The respondents experienced major (17\%) and minor (37\%) problems related to identifying, accessing, and coordinating resources (Table 2). Types and usefulness of available resources of information and resources were assessed (Table 3 and Table 4). The most cited source of information by parental caregivers was the HSCT team (87.7\%). In comments shared by the parental caregivers, the HSCT team was one of the best supports during the HSCT process to answer questions and helped make the experience manageable. Paradoxically, getting information about the transplant process and care requirements from the HSCT team was also identified as being a problem for $32 \%$ of parental caregivers. Information was obtained from books and other print materials (83.1\%) and the Internet (81.5\%); other sources were used much less frequently.

Given the high percentage of parental caregivers accessing the Internet, we further explored computer access. Internet access varied by location: home (86.5\%), hospital (74.8\%), and temporary housing (42.6\%); more than half of those with computer access also had broadband connections. Of the respondents with computer access, most used it for e-mail $(84.6 \%)$ and some used it for instant messaging $(27.7 \%)$. Some of the Web sites accessed included www.bmtinfonet.org (59.5\%), www.caringbridge.com (51.4\%), www.marrow.org (38.1\%), and www.supersibs.org (8.3\%); all of these sites were relevant to the HSCT process.

\section{Recommendations for HSCT Resources}

Parental caregivers were asked to reflect on and identify information and resources that would have been helpful to them in their role as a caregiver during the first year of transplant (Table 5). As more than one parent commented, "I wish I knew then what I know now." More than half of the respondents identified topics regarding managing the emotional and social impact of the transplant on their child, posttransplant and follow-up care, and practical strategies for caregiving, maintaining the family, and taking care of themselves during this first year. Resources regarding insurance problems were also identified as helpful, such as someone to help interpret their policy and understand what was and was not covered. Some parents commented on experiencing difficulties in finding relevant pediatric HSCT information, including providing posttransplant care follow-up; this was especially true for children who did not have cancer and in receiving emotional support for the child, 
family, and caregiver. Speaking to other parents dealing with HSCT was identified as one of the greatest resources in comments offered by a number of respondents.

\section{Discussion}

A needs assessment was completed by 161 parents of children who received a hematopoietic stem cell transplant. Parental caregivers reported a number of problems regarding identifying, accessing, and coordinating resources during the first year of the transplant process. These findings were very similar to the 2005 survey of 178 spousal caregivers of adults who received an HSCT, conducted by the National Marrow Donor Program (Peterson, 2007). Although spousal caregivers were slightly older than parental caregivers in this sample, with the majority of respondents between 40 and 59 years of age $(67.8 \%)$, they also were predominantly white $(95.5 \%)$ women $(72.6 \%)$. The 3 most accessed information sources were the same for spousal caregivers as parents and included the Internet (53.8\%), health care providers $(46.9 \%)$, and print materials $(45.6 \%)$, but the percentage of parents accessing and finding each resource as useful was higher for all 3 sources. Both parents and spousal caregivers were very similar in recommending much needed resources. Emotional issues of caregiving (79.9\%) and practical caregiving strategies (69.9\%) were the 2 topics identified as "must haves." The health issues of caregiving were similar in rankings $(49.4 \%$ for spousal and $42.8 \%$ of parental caregivers).

Stetz et al. (2006) identified concerns related to preparing for caregiving, managing care, facing the challenges, developing supportive strategies, and discovering unanticipated rewards and benefits of transplant. Even though parental caregivers in this study had more time to reflect on their needs (mean of 4 years) and the transplants were conducted almost a decade later than that reported by Stetz et al., they identified similar issues. Caregiver needs were also similar to themes identified by White (1994), whether the recipient was a child or an adult, and were related to the process of dealing with the transplant physically, psychologically, and socially for the individuals and families. These and other findings endorse the importance of recognizing the concerns of caregivers and anticipating the practical problems and understanding the family impact (Matsubara, de Carvalho, Canini, \& Sawada, 2007), especially on siblings (Wiener, Steffen-Smith, Fry, \& Wayne, 2007; Wilkins \& Woodgate, 2007), marital relationships, and social support needs of HSCT families. The transplant team, family, and friends provided the greatest support to the caregivers during the first year of the transplant process. Other important resources included information found on the Internet and other print materials. However, finding needed resources remained a challenge for more than half of the respondents. Health care providers can make resources more accessible by making available or referring caregivers to specific resources (best books and credible Web sites). It has been more than a decade since McDonald, Stetz, and Compton (1996) identified and made recommendations about the information and support needs of family caregivers. Many more resources are available today, but for some, unmet needs persist.

This study has 2 principal strengths: collaborating with a transplant-specific national advocacy group and conducting the survey online to reach a larger and geographically more diverse population. It should be noted, however, because the convenience sample was drawn from the advocacy group's listserv and respondents were predominantly white mothers, the results may not be generalizable to other families who do not have access to BMT InfoNet's online and print materials or do not have access to the Internet. In addition, there may be a bias in parents wanting to share their HSCT experience (either positive or negative). This study did not explore why participants did not use available resources, although it is worth noting that some of the formats (eg, attending workshops or seminars or receiving counseling) may require a physical presence to attend, which may be difficult when a child 
is hospitalized or in isolation. Respite or relief care might be useful in those situations; however, $38.4 \%$ of the respondents did not use these services when they were available and another $23.8 \%$ did not have access to them.

Families of transplant recipients are under considerable strain during the transplant process, needing support and resources to care for the transplant recipient, maintain family functioning, and care for the caregiver. Adequately and regularly assessing caregiver and family needs and providing resources to meet those needs during the transplant process, especially during transitions in care, is an important component of transplant care. Helping families connect with other transplant families may provide an important resource and source of support. The information from this survey is currently being used by the authors to develop and test a Web-based intervention to support parental caregivers. More research is needed to evaluate the impact of adequately addressing these needs on patient, caregiver, and family outcomes.

\section{Acknowledgments}

We would like to thank the parents who generously shared their time and experiences with us to help other families during transplant.

This study was funded by the American Cancer Society (RSGPB-02-186-01-PBP, Susan Parsons, principal investigator) and the National Cancer Institute (R01 CA119196, Susan Parsons, principal investigator).

\section{References}

Eldredge DH, Nail LM, Maziarz RT, Hansen LK, Ewing D, Archbold PG. Explaining family caregiver role strain following autologous blood and marrow transplantation. Journal of Psychosocial Oncology 2006;24:53-74. [PubMed: 17088241]

Eysenbach G. Improving the quality of Web surveys: the Checklist for Reporting Results of Internet ESurveys (CHERRIES). Journal of Medical Internet Research 2004;6:e34. [PubMed: 15471760]

Foxall MJ, Gaston-Johansson F. Burden and health outcomes of family caregivers of hospitalized bone marrow transplant patients. Journal of Advanced Nursing 1996;24:915-923. [PubMed: 8933250]

Grimm PM, Zawacki KL, Mock V, Krumm S, Frink BB. Caregiver responses and needs. An ambulatory bone marrow transplant model. Cancer Practice 2000;8:120-128. [PubMed: 11898136]

Matsubara TC, de Carvalho EC, Canini SR, Sawada NO. Family crisis in the context of bone marrow transplantation: An integrative review. Revista Latino-Americana de Enfermagem 2007;15:665670. [PubMed: 17923986]

Mayer, DK.; Jeruss, S.; Parsons, SK. Virtual synchronous focus groups. 2006 [Retrieved June 12, 2009]. from http://www.mednetcongress.org/fullpapers/MEDNET-19_MayerDeborah KA_e.pdf

McDonald JC, Stetz KM, Compton K. Educational interventions for family caregivers during marrow transplantation. Oncology Nursing Forum 1996;23:1432-1439. [PubMed: 8899760]

Parsons SK, Shih MC, Duhamel KN, Ostroff J, Mayer DK, Austin J, et al. Maternal perspectives on children's health-related quality of life during the first year after pediatric hematopoietic stem cell transplant. Journal of Pediatric Psychology 2006;31:1100-1115. [PubMed: 16150874]

Peterson, E. Caregiving for a blood or marrow transplant patient. Minneapolis, MN: 2007. (Report)

Stetz KM, McDonald JC, Compton K. Needs and experiences of family caregivers during marrow transplantation. Oncology Nursing Forum 1996;23:1422-1427. [PubMed: 8899758]

Sullivan-Bolyai S, Knafl KA, Sadler L, Gilliss CL. Great expectations: A position description for parents as caregivers: Part II. Pediatric Nursing 2004;30:52-56. [PubMed: 15022853]

Sullivan-Bolyai S, Sadler L, Knafl KA, Gilliss CL. Great expectations: A position description for parents as caregivers: Part I. Pediatric Nursing 2003;29:457-461. [PubMed: 14743843]

White AM. Parental concerns following a child's discharge from a bone marrow transplant unit. Journal of Pediatric Oncology Nursing 1994;11:93-101. [PubMed: 7917143] 
Wiener LS, Steffen-Smith E, Fry T, Wayne AS. Hematopoietic stem cell donation in children: A review of the sibling donor experience. Journal of Psychosocial Oncology 2007;25:45-66. [PubMed: 17360315]

Wilkins KL, Woodgate RL. Supporting siblings through the pediatric bone marrow transplant trajectory: Perspectives of siblings of bone marrow transplant recipients. Cancer Nursing 2007;30:E29-E34. [PubMed: 17876175]

Wochna V. Anxiety, needs, and coping in family members of the bone marrow transplant patient. Cancer Nursing 1997;20:244-250. [PubMed: 9265810] 
Table 1

Demographic Information $(\mathrm{N}=161)$

\begin{tabular}{|c|c|}
\hline \multicolumn{2}{|l|}{ Child HSCT recipient } \\
\hline $\begin{array}{l}\text { Age in years at the time of the HSCT } \\
\text { (mean, SD) }\end{array}$ & $8.3(5.7)$ \\
\hline Gender ( $\%$ male $)$ & $60.6(97 / 160)$ \\
\hline Reason for HSCT (\% cancer) & $80.8(130 / 161)$ \\
\hline Time since transplant (median, range), y & $4(1-20)$ \\
\hline Current status ( $\%$ doing well) & $61.2(82 / 134)$ \\
\hline \multicolumn{2}{|l|}{ Parental caregivers } \\
\hline Gender ( $\%$ female) & $86.7(137 / 158)$ \\
\hline $\begin{array}{l}\text { Age in years at the time of the HSCT } \\
(\% 30-49)\end{array}$ & $80.0(128 / 160)$ \\
\hline Race (\% white) & $96.2(150 / 156)$ \\
\hline Marital status at time of HSCT ( $\%$ married) & $88.8(142 / 160)$ \\
\hline Education $(\% \geq$ college $)$ & $61.8(97 / 157)$ \\
\hline Employment at time of HSCT (\% full-time) & $52.8(84 / 159)$ \\
\hline $\begin{array}{l}\text { Distance from transplant center (\%; lived } 1 \\
\text { or more days away) }\end{array}$ & $20.6(31 / 151)$ \\
\hline Other children at home $(\%)$ & $48.6(67 / 138)$ \\
\hline
\end{tabular}

NOTE: $\mathrm{HSCT}=$ hematopoietic stem cell transplant. 
Table 2

HSCT-Related Problems From the Caregiver's Perspective $(\mathrm{N}=161)$

\begin{tabular}{|c|c|c|c|}
\hline $\begin{array}{l}\text { Which of the Following Problems Did You Experience } \\
\text { At Any Time During the First Year of Transplant } \\
\text { as a Result of Your Caregiving Responsibilities: }\end{array}$ & Total Problems & Major Problems & Minor Problems \\
\hline Meeting personal needs ${ }^{a}$ & $86.9 \%(132 / 152)$ & $39.5 \%(60 / 152)$ & $47.4 \%(152)$ \\
\hline Helping with family's emotional needs $b$ & $86.3 \%(112 / 151)$ & $30.1 \%(46 / 153)$ & $56.2 \%(86 / 153)$ \\
\hline Managing household $b$ & $77.6 \%(118 / 150)$ & $32.2 \%(49 / 152)$ & $45.4 \%(69 / 152)$ \\
\hline Helping with child's emotional needs $c$ & $69.3 \%(104 / 150)$ & $19.3 \%(29 / 150)$ & $50.0 \%(75 / 150)$ \\
\hline Helping with family's physical needs $b$ & $66.6 \%(102 / 153)$ & $15.0 \%(23 / 153)$ & $51.6 \%(79 / 153)$ \\
\hline Communicating with and support from spouse $\mathrm{e}^{a, b}$ & $61.6 \%(93 / 151)$ & $23.8 \%(36 / 151)$ & $37.8 \%(57 / 151)$ \\
\hline Enough money for caregiving costs $b$ & $59.8 \%(92 / 154)$ & $26.0 \%(40 / 154)$ & $33.8 \%(52 / 154)$ \\
\hline Helping with child's physical needs ${ }^{c}$ & $59.0 \%(89 / 154)$ & $11.3 \%(17 / 151)$ & $47.7 \%(72 / 151)$ \\
\hline Finding resources and services $d$ & $58.7 \%(88 / 150)$ & $16.7 \%(25 / 150)$ & $42.0 \%(63 / 150)$ \\
\hline Modifying home ${ }^{d}$ & $41.2 \%(63 / 154)$ & $13.7 \%(21 / 153)$ & $27.5 \%(42 / 153)$ \\
\hline Getting help from friends $d$ & $40.3 \%(62 / 153)$ & $14.3 \%(22 / 154)$ & $26.0 \%(40 / 154)$ \\
\hline Getting help from family $d$ & $38.9 \%(60 / 154)$ & $14.9 \%(23 / 154)$ & $24.0 \%(37 / 154)$ \\
\hline Communicating with HSCT team $d$ & $32.3 \%(50 / 155)$ & $5.8 \%(9 / 155)$ & $26.5 \%(41 / 155)$ \\
\hline Getting HSCT information from health care providers $d$ & $29.8 \%(46 / 154)$ & $5.8 \%(9 / 154)$ & $24.0 \%(37 / 154)$ \\
\hline Adequate transportation ${ }^{d}$ & $27.8 \%(43 / 155)$ & $6.5 \%(10 / 155)$ & $21.3 \%(33 / 155)$ \\
\hline Number of problems (mean, SD) & $8.2(3.8)$ & $2.7(3.3)$ & $5.5(2.8)$ \\
\hline Median (range) & $10(0-15)$ & $1(0-14)$ & $6(0-13)$ \\
\hline
\end{tabular}

SOURCE: Categorized according to Sullivan-Bolayai's (2004) conceptual framework: a) maintaining self; b) maintaining the family unit; managing the illness; and d) identifying, accessing, and coordinating resources.

NOTE: HSCT = hematopoietic stem cell transplant.

${ }^{a}$ Maintaining self.

${ }^{b}$ Maintaining the family unit.

${ }^{c}$ Managing the illness.

$d_{\text {Identifying, accessing, and coordinating resources. }}$ 
Table 3

Caregiver Support Systems Throughout First HSCT Year $(\mathrm{N}=161)$

\begin{tabular}{|c|c|c|}
\hline & $\begin{array}{l}\text { Used } \\
(\%)\end{array}$ & Available $\begin{array}{r}\text { Not } \\
(\%)\end{array}$ \\
\hline Health care professionals & 87.4 & 4.0 \\
\hline Family & 84.9 & 8.6 \\
\hline Friends & 85.5 & 4.0 \\
\hline $\begin{array}{l}\text { Educational classes or materials on } \\
\text { HSCT }\end{array}$ & 83.4 & 6.0 \\
\hline Faith-based organizations & 71.7 & 4.6 \\
\hline $\begin{array}{l}\text { Support networks (talking with } \\
\text { others) }\end{array}$ & 72.2 & 4.0 \\
\hline $\begin{array}{l}\text { Support groups (in person, by phone, } \\
\text { or online) }\end{array}$ & 52.3 & 9.3 \\
\hline $\begin{array}{l}\text { Educational classes or materials on } \\
\text { caregiving }\end{array}$ & 47.0 & 17.2 \\
\hline Social services & 47.4 & 10.5 \\
\hline Financial assistance for caregiving & 47.0 & 23.2 \\
\hline Disease or transplant organizations & 40.1 & 14.5 \\
\hline Relief or respite care for child & 37.8 & 23.8 \\
\hline Transportation assistance & 20.5 & 15.2 \\
\hline Individual counseling & 29.0 & 15.8 \\
\hline Family counseling & 21.7 & 18.4 \\
\hline Caregiver organizations & 10.5 & 27.0 \\
\hline
\end{tabular}

NOTE: $\mathrm{HSCT}=$ hematopoietic stem cell transplant. 
Table 4

Resources Used by Parental Caregivers During HSCT Process ( $\mathrm{N}=161)$

\begin{tabular}{lcc}
\hline & $\begin{array}{c}\text { Used and } \\
\text { Helpful (\%) }\end{array}$ & $\begin{array}{c}\text { Did Not } \\
\text { Use (\%) }\end{array}$ \\
\hline HSCT team & 87.7 & 5.5 \\
Books/print materials & 83.1 & 6.1 \\
Internet & 81.5 & 14.4 \\
Other health care providers & 52.7 & 39.7 \\
Internet chats & 42.9 & 50.3 \\
Social services organizations & 21.9 & 67.8 \\
Caregiver support groups & 13.5 & 83.1 \\
Caregiver counseling & 11.6 & 84.4 \\
Telephone discussions/ & 10.9 & 87.1 \\
$\quad$ presentations & & \\
Workshops/seminars & 8.9 & 89.7 \\
Videos/DVDs & 6.1 & 89.2 \\
Total number resources/per & $4.2(1.8)$ & $6.1(1.8)$ \\
$\quad$ respondent & & \\
\hline
\end{tabular}

NOTE: $\mathrm{HSCT}=$ hematopoietic stem cell transplant. 
Table 5

Caregiver Recommended Resources for the HSCT Process $(\mathrm{N}=161)$

\begin{tabular}{lcc}
\hline & $\begin{array}{c}\text { Must } \\
\text { Have (\%) }\end{array}$ & $\begin{array}{c}\text { Not } \\
\text { Needed (\%) }\end{array}$ \\
\hline $\begin{array}{l}\text { Emotional/social issues for child } \\
\text { having HSCT }\end{array}$ & 68.2 & 2.7 \\
Posttransplant care and follow-up & 66.2 & 8.0 \\
Practical strategies & 63.6 & 8.0 \\
Emotional issues of caregiving & 58.9 & 7.3 \\
Insurance issues & 56.3 & 20.5 \\
Emotional/social issues for other & 53.0 & 4.6 \\
$\quad$ family members & & 12.5 \\
Health issues of caregiving & 42.8 & 19.7 \\
Financial issues & 41.5 & 10.9 \\
How to find community resources & 37.4 & 90.9 \\
How to connect with other parents & 36.4 & 13.9 \\
How to find support groups & 31.8 & 38.2 \\
\hline Legal issues of caregiving & 22.4 & \\
\hline
\end{tabular}

NOTE: HSCT = hematopoietic stem cell transplant. 